Bio - grafia. Escritos sobre la Biología y su Enseñanza. ISSN 2027

Edición Extraordinaria. p.p. 1080- 1089

Memorias del VIII Encuentro Nacional de Experiencias en Enseñanza de la Biología y la Educación Ambiental. III Congreso Nacional de Investigación en Enseñanza de la Biología.

\title{
Contribuições de componentes da licenciatura em Ciências Biológicas na constituição do educador ambiental
}

\section{Contributions of the components of the degree in biological sciences in the formation of environmental educators
Contribuciones de componentes del profesorado en Ciencias Biológicas en la constitución del educador ambiental

Gabriela de Vargas da Rosa1; Vidica Bianchi²; Maria Cristina Pansera de Araújo ${ }^{3}$

Resumo: A educação ambiental é uma construção histórica de valores e responsabilidades, num processo de mudanças de atitudes quanto a relação ser humano e natureza, considerando a vida em sociedade. O objetivo do trabalho é verificar a contribuição da formação profissional na Licenciatura em Ciências Biológicas para a constituição do educador ambiental, numa perspectiva interdisciplinar do conhecimento. Para tanto, foram realizadas as análises das ementas e referências dos componentes curriculares Ecologia, Prática de Ensino I: Fundamentos teóricos e práticos em ciências e Prática de ensino VI: Prática de Pesquisa Biológica inscritos no Projeto Pedagógico do Curso de Ciências Biológicas da Universidade Regional do Noroeste do Estado do Rio Grande do Sul (UNIJUI), implantado em 2009. As discussões propiciadas a partir deste conhecimento, em sala de aula, proporcionam espaços de reflexão sobre a responsabilidade individual $e$ coletiva na mudança de atitude quanto a relação com o ambiente.

Palavras chaves: Educação ambiental, Interdisciplinaridade, currículo.

Abstract: Environmental education is a historic building values and responsibilities in a process of attitudinal changes as the relationship between human beings and nature, considering life in society. The objective is to verify the vocational training contribution to the Degree in Biological Sciences for the establishment of environmental educators, an interdisciplinary perspective of knowledge. Therefore, we carried out the analysis of menus and references of curricular components Ecology, Teaching Practice I: theoretical
\end{abstract}

\footnotetext{
${ }^{1}$ Aluna do Curso de Licenciatura em Ciências Biológicas, na Universidade Regional do Noroeste do Estado do Rio Grande do Sul (UNIJUI).

${ }^{2}$ Doutora Professora do Curso de Licenciatura em Ciências Biológicas da Universidade Regional do Noroeste do Estado do Rio Grande do Sul (UNIJUI)

${ }^{3}$ Doutora Professora do Curso de Licenciatura em Ciências Biológicas da Universidade Regional do Noroeste do Estado do Rio Grande do Sul (UNIJUI)
} 
Bio - grafia. Escritos sobre la Biología y su Enseñanza. ISSN 2027

Edición Extraordinaria. p.p. 1080- 1089

Memorias del VIII Encuentro Nacional de Experiencias en Enseñanza de la Biología y la Educación Ambiental. III Congreso Nacional de Investigación en Enseñanza de la Biología.

and practical fundamentals in science and teaching Practice VI: Biological Research Practice enrolled in the Educational Project of the Course of Biological Sciences of the Regional University northwest of Rio Grande do Sul State (UNIJUI), introduced in 2009. The recommendations of the National Curriculum Standards to discuss cross-cutting and interdisciplinary environmental education were used. The discussions afforded from this knowledge in the classroom, provide spaces for reflection on the individual and collective responsibility in changing attitudes about the relationship with the environment.

Keywords Environmental education, interdisciplinaridad, curriculum

Resumen: La educación ambiental es una construcción histórica de valores y responsabilidades, en el proceso de cambio de actitudes en cuanto a la relación del ser humano con la naturaleza, considerando la vida en sociedad. El objetivo del trabajo es verificar la contribución de la formación profesional en el Profesorado en Ciencias Biológicas para la constitución del educador ambiental, en una perspectiva interdisciplinaria del conocimiento. Por lo tanto, se analizaron los programas y referencias de los componentes curriculares de Ecología, Práctica de Enseñanza I: Fundamentos teóricos y prácticos en ciencias y Práctica de enseñanza VI: Práctica de Investigación Biológica; inscriptos en el Proyecto Pedagógico del Curso de Ciencias Biológicas de la Universidade Regional do Noroeste do Estado do Rio Grande do Sul (UNIJUI) iniciado en 2009. Las discusiones que ofrece de este conocimiento en el aula, proporcionan espacios para la reflexión sobre la responsabilidad individual y colectiva en el cambio de actitud hacia la relación con el medio ambiente.

Palabras claves: Educación ambiental, interdisciplinariedad, curriculo.

\section{INTRODUÇÃO}

A educação ambiental é muito abordada, nos dias de hoje, e constitui-se uma construção histórica de valores, responsabilidades e mudanças de atitudes na relação ser humano, sociedade, vida e ambiente. Porém, as modificações são lentas e dependem das interações sociais estabelecidas. Portanto, é fundamental construir ações que possam mudar as relações cristalizadas pelos seres humanos com o ambiente. A constituição de sujeitos conscientes resgatará valores construídos, tais como a ética na convivência em uma sociedade sustentável e democrática. Cada cidadão é convidado a repensar suas ações para inovar e transformar o local onde vive, considerando o respeito, a cooperação solidária, a 
Bio - grafia. Escritos sobre la Biología y su Enseñanza. ISSN 2027

Edición Extraordinaria. p.p. 1080- 1089

Memorias del VIII Encuentro Nacional de Experiencias en Enseñanza de la Biología y la Educación Ambiental. III Congreso Nacional de Investigación en Enseñanza de la Biología.

diversidade social, em que as práticas dialógicas promovam novas atitudes individuais e coletivas, que permitam valorizar o ambiente (Jacobi, 1997).

A escola deve problematizar a relação com o ambiente, de modo que a educação ambiental instigue o aluno a compreender suas atitudes com outros seres vivos, consideradas corretas ou não. Segundo Vigotsky (1991), a reconstrução interna dos indivíduos, na interação externa (natureza, efeito estufa, ecossistema, recursos hídricos, desmatamento) constituirá os conceitos científicos, os valores e as práticas dos sujeitos em suas relações sociais e ambientais. Deste modo, Pimenta e Ghedin (2002) sinalizam que o professor tomado como educador deve ter a capacidade de refletir sobre suas atividades práticas de maneira que produza novas ações e reflexões.

$O$ objetivo foi verificar a contribuição da formação profissional na Licenciatura em Ciências Biológicas para a constituição do educador ambiental, numa perspectiva interdisciplinar do conhecimento.

\section{METODOLOGIA}

Foi realizada uma análise documental (Ludke \& André, 1986) do Projeto Pedagógico do Curso de licenciatura em Ciências Biológicas (PPCBIOLIC), implantado em 2009, da Universidade Regional do Noroeste do Estado do Rio Grande do Sul (UNIJU), Brasil. Neste PPC, foram analisadas as ementas de três componentes, que abordam questões ambientais e constituem-se num espaço e tempo de discussão das atitudes, procedimentos e valores a serem significados pela problematização da Educação Ambiental (EA): Ecologia; Prática de ensino I: Fundamentos teóricos e práticos em ciências e Prática de ensino VI: Prática de Pesquisa Biológica. Além disso, foram discutidos alguns excertos das narrativas das professoras (professora 1, professora 2 e professora3) destes componentes, a partir de seus diários de bordo.

\section{RESULTADOS E DISCUSSÃO}

As ementas dos componentes curriculares analisados não abordam a EA de forma direta, porém conceitos, métodos e práticas fundamentais para a formação do profissional são tratados ao articularem atividades interdisciplinares com conhecimentos específicos.

Componente Curricular Ecologia: 
Bio - grafia. Escritos sobre la Biología y su Enseñanza. ISSN 2027

Edición Extraordinaria. p.p. 1080- 1089

Memorias del VIII Encuentro Nacional de Experiencias en Enseñanza de la Biología y la Educación Ambiental. III Congreso Nacional de Investigación en Enseñanza de la Biología.

Ementa: (BIO-2009/1) Eco fisiologia (níveis de tolerância aos fatores abióticos $e$ adaptações a ambientes extremos); características das populações, (distribuição espacial, crescimento e fatores controladores dos tamanhos populacionais); interações entre populações: Herbivoria, parasitismo, parasitoidismo, predação e mutualismos; respostas adaptativas à pressão de inimigos naturais; competição; Estudo das comunidades: estrutura trófica, fixação e fluxo de energia, sucessão, diversidade. Estudo dos principais biomas mundiais; fitogeografia do Brasil; ciclos biogeoquímicos e grandes alterações ambientais e suas consequências.

Alguns aspectos referenciados na ementa, para a formação biológica do educador ambiental, são tratados, a partir dos estudos das interações entre as populações de diferentes seres vivos, que constituem as comunidades e os ecossistemas. $O$ tratamento dos conhecimentos necessários à compreensão do ambiente, para despertar uma consciência ecológica e ambiental entre as pessoas, emerge do diálogo estabelecido. Ao mesmo tempo aponta que as interações entre os seres vivos entre si e com o ambiente estão dinamicamente relacionadas e estruturadas, portanto precisam ser consideradas para que a vida humana possa manter-se "dinamicamente equilibrada". Por exemplo, a identificação das relações alimentares entre os seres vivos evidencia a interdependência entre eles e a organização da sociedade humana.

A incorporação dos estudos sobre ambiente na educação formal, em grande medida, limitou-se a internalizar os valores de conservação da natureza; em que "os princípios do ambientalismo se incorporaram através de uma visão das inter-relações dos sistemas ecológicos e sociais para destacar alguns problemas mais visíveis da degradação ambiental" (Leff, 1999: 119).

Deste modo, o componente de ecologia destaca os principais problemas ambientais ocorridos nos biomas mundiais, bem como nos ciclos biogeoquímicos, em que o efeito estufa (aquecimento da terra) é um processo natural e necessário para sobrevivência, sem o qual o planeta estaria permanentemente coberto de gelo. Porém com as atividades humanas, a emissão do gás carbônico vem aumentando gradativamente, o que eleva a temperatura média da terra, gerando o aquecimento global. As discussões, em sala de aula, proporcionam espaços de reflexão sobre a responsabilidade individual e coletiva nas mudanças de atitude na relação com o ambiente.

$\mathrm{Na}$ disciplina de Ecologia, os inúmeros temas subsidiam as articulações dos aspectos relevantes na construção da consciência ambiental pelos estudantes, com abordagens diversificadas para a formação do educador ambiental, numa abordagem conservacionista. 
Bio - grafia. Escritos sobre la Biología y su Enseñanza. ISSN 2027

Edición Extraordinaria. p.p. 1080- 1089

Memorias del VIII Encuentro Nacional de Experiencias en Enseñanza de la Biología y la Educación Ambiental. III Congreso Nacional de Investigación en Enseñanza de la Biología.

Observa-se que na medida em que o discente entende o funcionamento do ecossistema, passa a comprometer-se e engajar-se nas discussões com mais propriedade. Neste sentido, percebe-se também a ocorrência de pontos de ruptura, em que o acadêmico revela em seus depoimentos a transformação de pensamento frente ao ambiente, constituindo-se um Educador Ambiental.

Componente curricular Prática de Ensino I: Fundamentos teóricos e práticos em ciências

Ementa (BIO-2009/1) Atividade de campo que trabalha de forma interdisciplinar os vários ecossistemas, a partir de atividades propostas pelos professores. Aborda métodos básicos utilizados na caracterização física, química, geológica, geográfica e biológica desses sistemas. Reflexão teórica sobre a prática de campo, como instrumento de ensino aprendizagem em ciências no Ensino Fundamental.

Este componente enfatiza a educação ambiental no ensino fundamental de forma interdisciplinar, considerando a importância do trabalho escolar cooperativo, solidário e interdisciplinar. Tanto as questões práticas quanto teóricas tratadas constituem novas estratégias e pensamento pedagógico para a formação de cidadãos críticos e conscientes, numa perspectiva de educador ambiental. Para Morin (1984), uma "ciência com consciência" vem abrindo espaço pela atração e impulsão de novos paradigmas emergentes em campos científicos, num esforço articulador $e$ integrador para chegar a uma interpretação complexa do mundo. Ainda, destaca a importância do trabalho conjunto, enfatizando o esforço empreendido na elaboração de novos paradigmas para a formação do educador ambiental. Além disso, as atividades realizadas são questionadas quanto ao diálogo interdisciplinar estabelecido e a possibilidade de desenvolvimento destas ideias na educação básica.

Ao longo de uma experiência de 10 anos, na docência de Práticas de Pesquisa Biológica I e II, podem-se referenciar alguns aspectos importantes extraídos dos diários de bordo das pesquisadoras, como depoimentos de acadêmicos após a experiência vivenciada. A fala mais frequente dos estudantes é "aprendi mais nestes três dias do que o semestre todo em sala de aula" (professora 2). Isto leva a provocar a significação daquilo que foi estudado em sala de aula, articulando a teoria com a prática vivenciada. Outro depoimento diz "este componente deveria acontecer todos os semestres"(professora 3), pois cria novos contextos de discussão e compreensão dos conceitos científicos e provoca o repensar as interações com outros seres vivos e o ambiente, suscitando a reorganização do currículo.

Componente curricular Prática de ensino VI: Prática de Pesquisa Biológica 
Bio - grafia. Escritos sobre la Biología y su Enseñanza. ISSN 2027

Edición Extraordinaria. p.p. 1080- 1089

Memorias del VIII Encuentro Nacional de Experiencias en Enseñanza de la Biología y la Educación Ambiental. III Congreso Nacional de Investigación en Enseñanza de la Biología.

Ementa (BIO-2009/1) Atividade de campo que trabalha de forma interdisciplinar o estudo de ecossistemas, enfatizando o uso prático dos conhecimentos nos estudos dos diferentes sistemas biológicos, incluindo a elaboração e execução de um projeto sob orientação dos professores. Propor formas de trabalhar os conteúdos/conceitos no ensino médio a partir de atividades de campo.

Esta disciplina destaca o ensino teórico e prático do trabalho de campo, de forma interdisciplinar e fundamentado numa perspectiva de educação ambiental mobilizadora de conhecimentos específicos relacionados à qualidade de vida, que pode ser tematizada, no ensino médio. Ao discutir o manejo ambiental executado pelos seres humanos, problematizam-se questões identificadas no contexto em estudo, que provocam revisões na postura quanto a forma de utilização dos recursos ambientais, já que, muitas vezes, é desconsiderado o lugar do ser humano na teia da vida. A produção de um projeto de estudos, para ser vivenciado em diversos ambientes da área visitada: lavoura, remanescentes de mata, borda, timbozal, banhado, açude, córregos, valas, entre outros, nos três dias de trabalho de campo, possibilita o desenvolvimento de diversas etapas de uma pesquisa biológica, ao mesmo tempo em que problematizamos os cuidados com o ambiente e os seres que nele vivem. Entre os projetos desenvolvidos, a ênfase ocorre quanto aos artrópodes de solo e água; plantas arbóreas e herbáceas; aves e morcegos, o que provoca questionamentos sobre o sistema de identificação e classificação destes animais e plantas, bem como suas interações. Em cada projeto, indagações sobre metodologias de coleta, análise e conservação são propostas e discutidas pelo grupo envolvido. Estas situações facilitam a formação da consciência ambiental, pois cada projeto trabalha sobre a diversidade biológica nos locais estudados e as interações destes seres vivos entre si e com o meio, numa relação interdependente.

Nas duas disciplinas de Práticas de Ensino ( $I$ e VI) os professores salientam que os ambientes a serem estudados não são simplesmente objetos ou temas como é rotina nas aulas teóricas. Os locais das práticas são característicos da paisagem regional, com muitos impactos antrópicos (agricultura, pecuária, edificações), que coexistem com espaços ainda relativamente preservados, como florestas e banhados. Isso possibilita uma ampla reflexão sobre a concepção do ambiente como um sistema complexo de interações entre indivíduos, comunidades, sociedade humana, meio e natureza, colocando os seres humanos como parte deste, e não acima ou o centro do mesmo. A partir disso, discutem-se questões sociais, econômicas e sua relação com a qualidade e preservação ambiental, visando a sustentabilidade. 
Bio - grafia. Escritos sobre la Biología y su Enseñanza. ISSN 2027

Edición Extraordinaria. p.p. 1080- 1089

Memorias del VIII Encuentro Nacional de Experiencias en Enseñanza de la Biología y la Educación Ambiental. III Congreso Nacional de Investigación en Enseñanza de la Biología.

A aprendizagem desencadeada, na Prática de Pesquisa Biológica, promove articulações e discussões interdisciplinares, que suscitam conhecimentos conceituais de biologia, física, química e geologia, como modo de compreender a complexidade ambiental. Portanto, é necessário um currículo mais integrado e flexível, que valorize o conhecimento contextual, em que várias disciplinas sejam solicitadas a explicar as questões observadas (Capra, 2003).

A partir da Conferência das Nações Unidas sobre o Meio Ambiente de Estocolmo em 1972, - conceito de Educação Ambiental caracteriza-se pela perspectiva interdisciplinar. Nas disciplinas examinadas, a abordagem proposta nas duas práticas biológicas compromete os três professores envolvidos, na superação de sua "disciplinaridade", e provoca os estudantes a assumirem este compromisso. Olhar e estudar o ambiente a partir da sua complexidade e diálogos inter e transdisciplinares.

A ação interdisciplinar pressupõe mudanças de atitudes e capacidade de colocar-se, no lugar do outro, oportunizando a construção do processo coletivo, preparando indivíduos conscientes quanto a sua formação e a relação com a natureza, que o constitua como educador ambiental empoderado pela significação dos sistemas conceituais em estudo.

Leonir (1997) aponta a educação ambiental na formação do professor como primeira condição para que seja possível migrar de uma abordagem tradicional para uma interdisciplinar. Para ele, a interdisciplinaridade nasce da necessidade de responder aos problemas da sociedade, como a educação ambiental que precisa ser trabalhada na universidade, numa abordagem transversal, que permite a reflexão constante sobre o modo de vida instituído e as mudanças necessárias para o bem viver.

A interdisciplinaridade como concepção sistêmica da história de um evento e sua evolução deve articular os sujeitos e o ambiente, como propõe Morin (1984), numa relação interdependente e complexa, que aponta soluções existentes para alguns problemas e a busca de outras ainda desconhecidas.

O saber ambiental emerge como "um saber que, ao ultrapassar o campo da racionalidade científica e da objetividade operacional, obriga o próprio saber científico a abrir caminho a outras estratégias conceituais. Dessa maneira ocorre uma revalorização de um conjunto de saberes sem pretensão da cientificidade" (Leff, 2001, p.168).

Os princípios e valores ambientais que promovem uma pedagogia do ambiente devem ser enriquecidos com uma pedagogia da complexidade, que "induza os alunos a uma visão de multicausalidade e de inter-relações para observar o mundo nas diferentes etapas do 
Bio - grafia. Escritos sobre la Biología y su Enseñanza. ISSN 2027

Edición Extraordinaria. p.p. 1080- 1089

Memorias del VIII Encuentro Nacional de Experiencias en Enseñanza de la Biología y la Educación Ambiental. III Congreso Nacional de Investigación en Enseñanza de la Biología.

desenvolvimento psicogenético, que gerem um pensamento crítico e criativo baseado em novas capacidades cognitivas" (Leff, 1999: 119).

A compreensão ambiental pode ser entendida como a relação entre a sociedade e a natureza, o que implica em três níveis: do ser humano consigo mesmo e com o mundo; do ser humano com os outros, o que envolve o complexo histórico-sócio-cultural; e do ser humano com a natureza, em termos de substrato ecossistêmico. Esta visão, segundo Cuevas (2007. 485), requer integrar "o todo como elucidação dos processos naturais, sociais, econômicos além da articulação entre eles.

Nesse sentido, entende-se que a promoção de discussões teóricas e atividades práticas visando a EA, na escola básica, perpassa a tematizações ocorridas nos diferentes momentos de sua formação, que lhes possibilitem integrar os conhecimentos disciplinares articulados as questões sociais e tecnocientificas. Para que as disciplinas Ecologia, Prática de Ensino I: Fundamentos teóricos e práticos em ciências e Prática de ensino VI: Prática de Pesquisa Biológica, não estejam "a toa, sem sentido (registro do Diário de Bordo, professora 1)", no currículo e possam contribuir para a compreensão da EA, defende-se que é urgente discutir a formação inicial de professores para a educação básica. Devem-se problematizar os processos formativos e enfrentar o reducionismo, que se apresenta em muitas práticas educativas ambientais, como aquelas pouco reflexivas ou que supervalorizam a teoria em detrimento da observação prática qualificada. 
Bio - grafia. Escritos sobre la Biología y su Enseñanza. ISSN 2027

Edición Extraordinaria. p.p. 1080- 1089

Memorias del VIII Encuentro Nacional de Experiencias en Enseñanza de la Biología y la Educación Ambiental. III Congreso Nacional de Investigación en Enseñanza de la Biología.

\section{CONSIDERAÇÕES FINAIS}

A Educação Ambiental é um processo, longo e trabalhoso, em que não podemos mudar as concepções das pessoas de imediato, porém devemos questionar e provocar reflexões para que revejam as suas atitudes, quanto as relações estabelecidas com os diversos ecossistemas e a biodiversidade do planeta, como um todo e na área especifica, onde vivem.

Portanto, a educação ambiental deve ser trabalhada considerando-se as dimensões sociais, econômicas e ecológicas, em que ocorre a articulação dos diversos saberes pedagógicos da formação profissional e da atuação na Educação Básica. Desta forma, podemos proporcionar a mudança de atitudes para construir ainda na infância saberes ecológicos sustentáveis, que poderão transformar a realidade ambiental, visando o desenvolvimento sustentável. $\grave{A}$ medida que os sujeitos se reconhecem como educadores ambientais, constituídos pela discussão proporcionada nos componentes curriculares do curso de Licenciatura em Ciências Biológicas, bem como em outros espaços de educação formal ou não, as mudanças nas relações entre os sujeitos e a natureza efetivam-se provocando aprendizagens significativas. 
Bio - grafia. Escritos sobre la Biología y su Enseñanza. ISSN 2027

Edición Extraordinaria. p.p. 1080- 1089

Memorias del VIII Encuentro Nacional de Experiencias en Enseñanza de la Biología y la Educación Ambiental. III Congreso Nacional de Investigación en Enseñanza de la Biología.

\section{REFERÊNCIAS BIBLIOGRÁFICAS}

BRASIL,1998, Parâmetros Curriculares Nacionais. Ensino Fundamental, Brasília, Brasil, Mec./Sef.

CAPRA, F. 2003, Alfabetização ecológica: O desafio para educação do século XXI, Rio de Janeiro, Brasil.

CARVALHO, C. 2001, Ecologia e desenvolvimento, Rio de janeiro, Brasil, Terceiro milênio.

CUEVAS, R.M.R. 2007. Interdisciplina, complejidad y formación ambiental. In Perspectivas da educação ambiental ibero-americana: Conferencias do $V$ Congresso Ibero-Americano de Educação Ambiental - Joenville, SC. Rio de Janeiro: Associação Projeto Roda Viva.

FLORIANI, D., KNECHTEL R. M.2003, Educação ambiental, Epistemologias e metodologias. Curitiba, Brasil.

JACOBI, P. et al. (orgs.)1997. Educação, meio ambiente e cidadania: reflexões e experiências. São Paulo, Brasil, SMA.

LEFF, Enrique. 1999 (p.111-129). Educação ambiental e desenvolvimento sustentável. In REIGOTA, Marcos (org.). Verde cotidiano: o meio ambiente em discussão. Rio de Janeiro, Brasil, DP\&A.

LEFF, Enrique. 2001 Saber Ambiental: sustentabilidade, racionalidade, complexidade, poder, Rio de Janeiro, Brasil, Vozes.

LEONIR, Y. 1997A importância da indisciplinaridade na formação dos professores de ensino fundamental: São Paulo, Brasil. Caderno de pesquisa, fundação Carlos chaga.

LUDKE, M.; ANDRE, M. 1986 Pesquisa em educação: abordagens qualitativas. São Paulo, Brasil: EPU.

MORIN, Edgar, 1984, Ciencia com consciência, Barcelona, Espanha: AnthroposPIMENTA, Selma Garrido e GHEDIN, Evandro (Orgs.)2002. Professor Reflexivo no Brasil - Gênese e crítica deum conceito. - São Paulo,Brasil: Cortez,

VIGOTSKY, L.,1991 A Formação social da mente. São Paulo, Brasil: Martins Fontes. 